\title{
Use of Music and Songs as Pedagogical Tools in Teaching English as Foreign Language Contexts
}

\author{
Tribhuwan Kumar ${ }^{D},{ }^{1}$ Shamim Akhter $(D),{ }^{2}$ Mehrunnisa M. Yunus $\left(\mathbb{D},{ }^{3}\right.$ \\ and Atefeh Shamsy iD ${ }^{4}$ \\ ${ }^{1}$ Department of English, College of Science and Humanities at Sulail, Prince Sattam Bin Abdulaziz University, Al Kharj, \\ Saudi Arabia \\ ${ }^{2}$ School of Languages, Civilisation and Philosophy, Universiti Utara Malaysia, Changlun, Malaysia \\ ${ }^{3}$ Department of English, College of Science and Humanities at Sulail (Girl's Section), Prince Sattam Bin Abdulaziz University, \\ Al Kharj 11942, Saudi Arabia \\ ${ }^{4}$ English Department, Abadan Branch, Islamic Azad University, Abadan, Iran
}

Correspondence should be addressed to Atefeh Shamsy; atefehshamsy@yahoo.com

Received 7 December 2021; Accepted 9 February 2022; Published 27 February 2022

Academic Editor: Ehsan Rezvani

Copyright (c) 2022 Tribhuwan Kumar et al. This is an open access article distributed under the Creative Commons Attribution License, which permits unrestricted use, distribution, and reproduction in any medium, provided the original work is properly cited.

\begin{abstract}
The purpose of this research paper is to demonstrate how music can be used in the classroom by describing several methods and providing resources, as well as to demonstrate why music can benefit foreign language learning by reviewing research on the impact of music-related methods on EFL learning and teaching. The researchers relied upon the previous studies and critical and scholarly texts. This study adopts a descriptive study design, which is comprised of a quantitative study in various contexts. The results demonstrated that the complexity found in the foreign language teaching process emerges from the social and cognitive needs of the EFL learners that in most cases are ignored intentionally or unintentionally. Moreover, the process of second language learning comes with a lot of anxiety and peer pressure. Hence, it is concluded that song and music can certainly be considered as one of the useful language learning tools that aid second language teaching without putting a lot of academic pressure on the learners. The implication that can be inferred is that English teachers need to offer a learning environment that is anxiety free and at the same time serves the purpose of learning through fun activities. Songs and music can be proven to be an effective listening activity that has multiple benefits to offer. Particularly in the case of young and elementary learners, music has been used widely to teach important concepts in a fun way by second language teachers.
\end{abstract}

\section{Introduction}

Music has always been a uniting cultural phenomenon throughout human history. Every cultural practice carries significant information about the respective culture and individuality. Music and songs do not have a single purpose of entertaining; instead they also offer a diverse range of educational functions. It is observed that teaching English as a foreign language to the learners who have a different first language is not merely a simple process of teaching language. The complexity found in the second language teaching process emerges from the social and cognitive needs of the learners that in most cases are ignored intentionally or unintentionally $[1,2]$. Moreover, the process of second language learning comes with a lot of anxiety and peer pressure. Hence, English teachers need to offer a learning environment that is anxiety free and at the same time serves the purpose of learning through fun activities [3, 4]. Songs and music can certainly be considered as one of the useful language learning tools that aid second language teaching without putting a lot of academic pressure on the learners.

Moreover, songs and music can be proven to be an effective listening activity that has multiple benefits to offer. Particularly in the case of young and elementary learners, 
music has been used widely to teach important concepts in a fun way by second language teachers. One of the many benefits of using music and songs in teaching English is that teachers can acquire the focused attention of learners as well as keep them excited for learning. Since like any other language learning process, English also requires a significant amount of repetition to practice the sounds and structures; songs and music help to offer this opportunity as repetition is one of their significant features [5-7].

Songs do not only offer language practice opportunities through repetition but also by developing listening skills, language association and assimilation skills, and phonological skills and provide an easygoing learning atmosphere. Hence, many linguistic features can be recycled through using songs while teaching English. Songs can be diffused into different stages of lessons as warm-ups or fillers to keep the students interested in the lesson $[8,9]$. Given the usefulness of the songs, this paper aims to analyse the pedagogical functions of music and songs in teaching English as a second or foreign language. The paper describes the educational functions of music and songs in English teaching by reviewing the researches in the field of learning English as a foreign language (EFL) and teaching English as a foreign language (TEFL).

\section{Purpose of the Research}

Every research study has a specific goal and a specific topic that it intends to learn. The goal of the research is what makes this study important. In a nutshell, the following are the objectives of the research:

(i) To explore the prevailed intelligences and areas in EFL teaching and its complexities in teaching and learning English language

(ii) To investigate how and why music can be used in a foreign language classroom to assist students attain a variety of learning goals, such as improved grammar, pronunciation, and vocabulary

(iii) To determine the existence of the positive relationship between multiple intelligences of learners and pedagogy

\section{Literature Review}

Various researches done previously on the "multiple intelligences and EFL teaching" and "EFL teaching and use of music and songs." Still the effectiveness of the use of music and songs in EFL classrooms is in question. According to previous studies, teachers are generally supportive of the use of music in foreign language (FL) classrooms. Teachers rarely include music into their classes, despite a generally positive opinion regarding the use of music in the foreign language classroom among students $[10,11]$. These findings are attributed to two key factors: a lack of understanding regarding adaptable content and a lack of theoretical support for the use of music in foreign language classrooms, according to the findings of the studies. Because of this, the researchers are attempting to analyse approaches and give recommendations for potential EFL educational materials.

3.1. Multiple Intelligences and EFL Teaching. Garner and Alexander [12] consider that students cannot be evaluated or taught on the basis of assumptions that they all have a similar kind and level of intelligence. They have divided intelligence into eight different categories and named this division "Multiple Intelligences." Further research by Armstrong [13] believes that all students can excel in all these eight categories if their abilities are addressed properly. These multiple intelligences when made part of the educational syllabus can offer teachers prospects to create and adopt new teaching techniques that are more compatible with student's respective needs $[14,15]$. Each category of intelligence can be used to aid learning in multiple other fields. In this regard, Armstrong [13] has presented forty different strategies to apply in different educational contexts of learning (Table 1).

Christison [16] has established Lazear's [17] guide for instructors to include and develop learners' intelligence. Lazear [17] suggests that teachers should be trained for special skills like adapting and developing content that is compatible with learners' metacognition and intelligence. A follow-up study by Hou [18] has also tried to investigate the role of multiple intelligences in the performance and output of EFL learners. He tested around 2400 college junior-level EFL students from Taiwan. He structured two different sets of questions to measure students' listening (35 questions) and reading (40 questions) skills at the start of the semester, followed by a questionnaire consisting of 170 questions to measure the categories of intelligence each student belonged to. The final results supported the fact that multiple intelligences constitute a huge part of the learning process of EFL students. The study also concluded that multiple intelligence teaching strategies aid EFL students to learn better. The involvement of music and vocabulary games combined with outdoor activities proved to be the best learning atmosphere for EFL students [19].

Hajhashemi et al. [20] conducted a similar but more relationship-focused study to investigate the link between multiple intelligences and reading proficiency of students in the Iranian EFL learning context. The study selected 128 precollege EFL students through a random sampling technique. Two tests including a demographic test for competition and translated version of McKenzie's MI test were used to measure student's intelligence. To measure reading comprehension, a paper-based test adapted from TOEFL with eleven multiple-choice questions was used. The results revealed that a strong relationship existed between the reading proficiency and multiple intelligences of students.

Moreover, numerous studies have shown results supporting the existence of the positive relationship between multiple intelligences of learners and pedagogy. For example, a study conducted by Baş and Beyhab [21] showed that learners show better achievement of learning objectives when they are taught through teaching processes that incorporate multiple intelligences teaching practices. The researchers took a pretest to conduct a comparison between 
TABLE 1: Teaching strategies for multiple intelligences [13].

\begin{tabular}{|c|c|c|}
\hline $\begin{array}{l}\text { Type of } \\
\text { intelligence }\end{array}$ & Example & Teaching strategies \\
\hline Linguistic & $\begin{array}{l}\text { Strategies should lay emphasis on unrestricted language } \\
\text { practices that will foster the linguistic aptitude in learners. }\end{array}$ & $\begin{array}{l}\text { Storytelling: it needs the use of imagination. It is a dynamic } \\
\text { instrument to "weave" the information envisioned to teach } \\
\text { into a thought-provoking story that can have learners } \\
\text { engaged. }\end{array}$ \\
\hline $\begin{array}{l}\text { Logical/ } \\
\text { mathematical }\end{array}$ & $\begin{array}{l}\text { Strategies should include rational critical thinking skills } \\
\text { and the application of proficiency in classrooms. }\end{array}$ & $\begin{array}{l}\text { Socratic questioning: it helps students "sharpen their own } \\
\text { critical thinking." It consists of the critical thinking process } \\
\text { of Socrates. A teacher acts as the questioner, questioning } \\
\text { students' beliefs and views about the world and how it } \\
\text { functions. }\end{array}$ \\
\hline Spatial & $\begin{array}{c}\text { Strategies should be focused on dealing with learners' } \\
\text { internal and external images through the integration of } \\
\text { imagination, movies, illustrations, visual novels and } \\
\text { cryptograms. }\end{array}$ & $\begin{array}{c}\text { Graphic symbols: it consists of assigning symbols to ideas. } \\
\text { For example, drawing real roots under the roots word of } \\
\text { vocabulary. Thus, students connect the symbol to the root of } \\
\text { the word. }\end{array}$ \\
\hline $\begin{array}{l}\text { Bodily/ } \\
\text { kinaesthetic }\end{array}$ & $\begin{array}{l}\text { Tactics should enhance learners' physique and movement } \\
\text { in the classroom to attain a better understanding of the } \\
\text { ideas taught. }\end{array}$ & $\begin{array}{l}\text { The classroom theatre: it necessitates learners' talent of } \\
\text { acting through dramatizing a problem or an idea in action. }\end{array}$ \\
\hline Musical & $\begin{array}{l}\text { Strategies should develop music into lessons. Such } \\
\text { strategies will help learners accumulating information in } \\
\text { their long-term memory. }\end{array}$ & $\begin{array}{l}\text { Discographies: it entails the application of already } \\
\text { prevailing recorded musical fragments to impart ideas or } \\
\text { open conversation or teach vocabulary. }\end{array}$ \\
\hline Interpersonal & $\begin{array}{l}\text { Strategies should foster } \\
\text { sense of fittir }\end{array}$ & $\begin{array}{l}\text { Board games: they can train learners for informal social } \\
\text { interaction. A teacher can plan a game conferring to the } \\
\text { topic or they can just utilize already present games. }\end{array}$ \\
\hline Intrapersonal & $\begin{array}{l}\text { Strategies should comprise activities and directions that } \\
\text { aid learners to experience themselves independently and } \\
\text { internally. }\end{array}$ & $\begin{array}{l}\text { Personal connections: it entails making the link between } \\
\text { what is being imparted and students' individual lives. }\end{array}$ \\
\hline Naturalist & $\begin{array}{c}\text { Strategies should consist of more outdoor activities and } \\
\text { plans. They also should let students to carry the external } \\
\text { world into class. }\end{array}$ & $\begin{array}{l}\text { Eco study: it involves the incorporation of nature in the } \\
\text { prospectus whether it is math or linguistic studies. It needs } \\
\text { the acknowledgement of the link between topic and ecology. }\end{array}$ \\
\hline
\end{tabular}

traditional EFL classrooms and multiple intelligence-supported classrooms. Around fifty students divided into two classes were taught for four weeks using a curriculum designed by researchers. One class was taught by using multiple intelligences incorporated coursework and the other class was taught by using traditional EFL content for lectures. Where the pretest did not show any significant differences, the posttest showed clear differences in the language skills of both classes. The multiple intelligences supported EFL classroom scored 74.6 whereas traditional EFL class scored 60.2 in their posttests. Another major study focusing on the similar relationship between linguistic and musical intelligence was conducted by Khaghaninejad and Hosseini [22]. The study found a positive relationship between musical and linguistic intelligence. The findings revealed that students had a high level of lexicon awareness when taught through music, rhymes, and songs.

3.2. EFL Teaching and Use of Music. Teaching English as a foreign language involves achieving a diverse range of learning objectives including excelling at grammar, pronunciation, and vocabulary. The bigger picture of English language learning is dependent on the crucial fundamentals such as vocabulary and pronunciation. Particularly vocabulary is considered as the heart of language learning as well as its use [23]. Considering the importance of vocabulary in the process of learning English as a foreign language reveals that it also has a crucial role in the teaching in EFL context. However, Richards and Rodgers [24] have described that in the past teaching vocabulary and pronunciation were not given any special focus or little in almost all second language programs. On the other hand, English language programs currently have focused on renewing the interest in the importance of vocabulary and pronunciation learning as well as teaching.

The present English language programs divide learning and teaching vocabulary into three general categories presented by Beglar and Hunt [25]. The first is known as unintended learning where words are learned as a by-product of other unintentional activities, such as reading and listening. The second one is referred to as intentional or direct learning by investigating the learners' vocabulary needs and prescribing them a certain list of words to develop their linguistic knowledge. The third one is based on learners' independent strategy development by exercising guessing the meaning of different words from both linguistic and social contexts as well as enabling learners to use dictionaries.

There are different pedagogical approaches to teach and learn English vocabulary found in the methodological course books. For example, Abdelrady et al. [26]; Çakmak et al. [27]; and Weatherford [28] have suggested numerous techniques for teaching vocabulary in EFL classrooms. These techniques consist of utilizing visual aids, role-playing and rehearsals, context and culture-focused vocabulary, learning new words through art activities, mnemonic, keyword techniques, and 
semantic approach. The other two major techniques include teaching new words through music by using simple songs and the desuggestopedia method as well as direct physical response and involvement. One of the interesting pedagogical tools for teaching and learning vocabulary is music. Previous researchers such as Reeve and Williamson [29] and Giudice [30] have also supported the significance of songs in increasing students' motivation to learn English and also enhancing their focus in the classroom. Hubbard et al. [31] and Murphey [32] have highlighted high memorability as the most significant advantage offered by songs in learning English vocabulary. According to Murphey [32]; songs aid both long and short-term memory as usually it is difficult to remember everything during learning another language, and only songs from the respective language stick to the learners' brains. Studies have shown that the use of songs has been particularly effective in teaching the English language to young learners. The reason behind this can be supported by Piaget's [33] understanding of egocentric language that explains the fondness of children for songs as they enjoy repeating themselves since they love hearing themselves and have little or no concern for the recipient. A similar kind of effect on adult learners can also be explained under the same theory as Piaget [33] has observed that "it is possible that need for egocentric language never leaves humans even when they grow up into adults and this need is satisfied through songs." Krashen [34] has also suggested that learning language through involuntary repetition can be proof in the support of the existence of Chomsky's language acquisition device. Murphey [32] further strengthens this assumption and suggests that songs may stimulate the repetition function of this language acquisition device, especially in the case of children who can learn songs smoothly.

\section{Methodology}

This research employs a descriptive study design with an element of qualitative analysis. The researchers acquired data for this study by researching previous research, theoretical perspectives, and resources for music-related EFL teaching methods. The researchers review the literature about the use of music in the EFL classroom. They explored various researches related to the positive relationship between multiple intelligences of learners and pedagogy techniques related to songs and music.

\section{Discussion}

After reviewing the studies on the relationship between music and EFL teaching and learning, the reasons behind using the music in EFL classrooms from various perspectives can be listed as follows.

5.1. Motives behind Using Music in EFL Classrooms. Kuśnierek [35] explains that there are two major motives behind using music in English language teaching classes including motives to meet the cognitive needs of the learners as well as to enhance effectiveness. The Krashen Affective Filter Hypothesis (1982) describes these affective factors as an explanation for the differences between the learning abilities of two learners. This is further explained by Saricoban and Metin [36] who have observed that songs can enhance the performance of EFL learners in all four linguistic areas concerned with listening, writing, speaking, and reading. However, to ensure this enhancement, students are required to develop a positive attitude towards the overall learning process. Krashen [34] explains that the presence of a positive attitude towards learning proves the existence of a weak affective filter. Music can aid in creating a positive attitude by offering an easy-going learning atmosphere hence mitigating the affective filter. This impact of music in creating a helpful atmosphere for learning language has been investigated and proved by different other researchers including Griffee [37]; Gardner [38]; Domoney and Harris [39]; and Speh and Ahramjian [40]. Eken [41] has presented the right different motives behind using song and music in EFL classrooms (Figure 1).

The above motives indicate that using songs in EFL classroom settings can guide learners towards instinctive identification and the use of different language constituents. Kuśnierek [35] explains that this automatic process is quick and well persistent as it takes place involuntarily without indulging the attention of the learner. Hence, songs can be proven to be useful to aid this automation process of language. Fundamentally, learners should be offered an environment where the communicative usage of the target language is likely.

5.2. Advantages of Using Music and Songs in the EFL Classrooms. Teachers often express mixed opinions on using music in EFL classrooms. Few teachers consider that using music for teaching English can make the learning environment a little overwhelmed and there is a possibility that complex lyrics would add difficulty and confusion rather than helping learners to understand language. However, the other group of teachers holds an opinion of the positive impact of music in class only for children with musical intelligence. According to these teachers, music is only useful in EFL classrooms for a particular group of musically exceptional learners. There is no doubt that students with superior musical cognitivism will be able to memorize and remember new words faster than those who do not have exceptional musical intelligence, but it cannot be assumed that there will be zero benefits of using music in EFL classroom for learners without any musical intelligence [42]. There are the following multidimensional pedagogical benefits highlighted by different research studies.

5.2.1. Psychological Advantages. Both music and language are systems of symbols and sounds. In both systems, sounds are considered to be important communicative signals to convey significant information to a person. Language particularly fulfills four different purposes as a communicative tool. First, it aids as a source of cognition; second, it is a curator of the respective culture; third, it is the primary tool for communicating and expressing ideas. Lastly, it is also the only tool that enables the exchange of ideas among members 


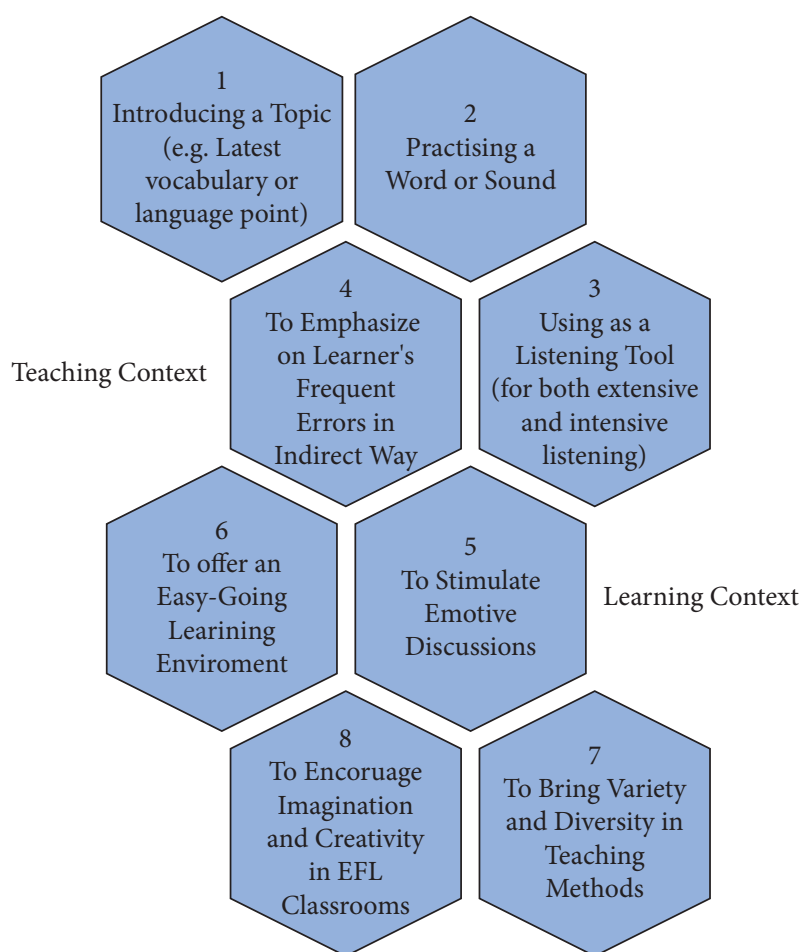

FIGURE 1: Eight motives behind using songs in EFL classrooms by Eken [41].

of a certain culture. Both language and music are highly emotive in their nature and are closely interconnected.

The use of songs in the EFL classroom helps to create a psychological environment that works in favour of learners by reducing learning anxiety and activating the brain's hemisphere linked to language learning, thus promoting the learners' interest in the English language. The use of songs can affect the psychological state of EFL learners in terms of motivation, positive environment, and multiple intelligences linked with effective language learning. Kuśnierek [35] believes that songs can work as a tool to motivate EFL learners for learning English as popular songs from a different language offer learner an opportunity to relate to different daily life experiences as well as cultures outside their classrooms. Furthermore, music is also one of the effective ways to influence EFL learners' emotions and behaviours as they do not interpret singing as an academic obligation or process. Instead, they perceive it as a recreational activity or game for unwinding. The use of music and songs serves the dual function of relaxing the learners and at the same time enabling unintentional vocabulary acquisition. Kuśnierek [35] describes that the reason behind this smooth involuntary acquisition of vocabulary is that EFL learners associate songs with recreational and fun; hence, a peerpressured activity of language learning in presence of music are associated with a pleasant experience.

The other link that can offer an explanation of the cognitive advantages of music in the EFL context is between multiple intelligences and English songs as a listening exercise. As stated in the literature review (Table 1), Gardner
[38] has divided intelligence into eight different types. He has believed that all of these eight categories of intelligence are closely interrelated and cannot be studied in isolation as one affects the other.

During the process of teaching English to EFL learners, teachers do not necessarily need to rely only on songs and music, but they can also add visual clips in form of videos and cartoons to encourage the learners to imitate the activities displayed to them. For example, students can be encouraged to repeat the lyrics of a song. All these activities play a helpful role for the cognitive systems of learners by aiding the memorization and comprehension of the language-related content as all probable means of observation of information is being utilized. The presence of novel and intricate information along with the struggle to eliminate distractions in perceptions helps learners to develop new channels of information that they have not necessarily advanced yet. Using both songs and videos enable EFL learner to utilize both audio and visual channels of their perceptions to intake the sounds of English language. Combining English phrases with a dancing or playing activity aids EFL learners with kinaesthetic intelligence to memorize the English words as well as phrases important to perform a song or game.

5.2.2. Pedagogical Advantages. Songs can offer a diverse range of pedagogical advantages both in terms of cultural and linguistic knowledge. The two basic constituents that help develop a better song are wordplay and music. Hence, the conditions of acquiring language in the EFL context by utilizing the systems of songs are quite similar to the process of working with text. It is to be noted that the lyrics of any song can be both less or more meaningful in the given semantic context. The text of few songs offers a huge amount of cultural or historical information, common ground, and ideas for intellectual discussions including philosophical ponderings about the song writer's life. All this information including lyrics and background knowledge can be valuable linguistic knowledge that is rich in vocabulary, with repeated grammatical structures and phrases along with a diverse range of stylistic and pragmatic expressions that are easy to remember and memorize due to music [43]. The cultural or historical knowledge offered by songs can also help to enhance the emotional intelligence of EFL learners.

The other significant pedagogical advantage of using songs in EFL classrooms is their linguistic usefulness in terms of providing instant new words, pronunciation, and syntactic knowledge that EFL learners acquire unintentionally with no intended implication. Moreover, Baoan [44] describes the moralistic role of music in elevating student's morale as also appreciated by teachers since it helps them to keep the EFL learners indulged and interested. Hence, offering unique forms of communication in terms of linguistics features that have both melodic and rhythmic value songs tends to aid EFL classroom learning. Gubina [45] explains that listening to songs may appear as a simple pleasant activity but alongside this recreational activity, there are multiple cognitive integrations taking place. This cognitive integration includes language assimilation, 
expansion of vocabulary, and contextualization of both new and old words, and better correlations of current knowledge are established with prior knowledge. There are songs specially composed for the language training purpose for EFL learners in order to teach the most common and reoccurring grammatical structures. These songs have rhythmic lyrics, with linguistic explanations and comments accompanied by language exercises and tasks to measure the understanding of content by EFL learners. In a nutshell, songs contribute greatly in excelling pronunciations and accentual intonation of the English language. The repetitive grammatical phrases help EFL learners to assess themselves for right pronunciation and articulation.

5.3. Music and Songs as an Answer to Diverse Pedagogical Problems. As it has been mentioned in earlier sections, songs offer a wide range of advantages for EFL teachers and students by expanding their linguistic knowledge as well as the positive moral impact on learners group subtleties. There are also various scenarios where teaching English to nonnative speakers is difficult, but if the teacher is also nonnative, the task becomes rather challenging. On the other hand, multiple other questions arise such as in the presence of both teacher and learner who are teaching and learning English as a foreign language, what language should be preferred to communicate? In these specific scenarios, the audio and visual aid comes to the rescue. Particularly, music becomes an effective tool to communicate and develop interaction between EFL learners and teachers who do not share the same first language. There are the following effective uses of music as a communication tool offered by Vishnevskaia and Zhou [46] in the abovementioned special EFL cases.

\subsubsection{Connecting Tool between EFL Teachers and Learners.} Vishnevskaia and Zhou [46] have offered their experience as an example in this regard. They have stated the difficulties faced in teaching Chinese EFL students by a Russian EFL teacher. The Chinese EFL learners most of the time feel scared of foreigners especially when the EFL teachers appear distinguishable in terms of ethnicity from the average Chinese individual. Using songs for teaching English has helped Chinese EFL students to understand and realize that each individual has its own particular features and they can represent different cultures and perspectives of the same world. This can help to enhance learners' intercultural aptitude. Hence, a song plays a role of the sociophysiological bridge that helps to support the stability in the everchanging groups of learners. Moreover, in this specific scenario, a nonnative EFL teacher should investigate the songs which are more familiar to EFL learners and use them to build their linguistic foundations. Furthermore, during the early stages of building an academic relationship between a foreign teacher and EFL learners, music can play a significant role to encourage decent and quick connections. In order to make students feel comfortable and not overwhelmed with a lot of knowledge, it is better to choose simple and shorter songs.

\subsubsection{Disintegrating Tool for Monotonous Language} Templates. The biggest challenge to overcome while teaching English is dealing with the lack of variety in the available language templates. Case in point, Vishnevskaia and Zhou [46] share that in China if the students are asked "how are you?" the frequently repeated answer is "I'm fine, thank you, and you?" Since there are multiple songs on the topic of greetings that can be used in English language teaching, this offers a diverse range of choices for EFL students to learn instead of the same staple expressions of greetings. These greeting songs vary both in their levels of complexity and variation in terms of vocabulary. The criteria to choose the song highly depends on the age and aptitude of EFL learners. For example, for kindergarten EFL learners, there are songs that offer single phrase answers with subtitles for the respective aptitude of the children. Similarly, for older children, songs with complex sentences and multiple possible answers are used. Before teaching these songs to EFL learners, teachers need to accompany these songs with respective physical gestures and movements. Once both audio and physical cues are decided, the teacher can ask EFL learners to repeat the lyrics with respective actions, for example, to clap and slap their hands gently on stomach followed by saying "I am hungry" or smile followed by "I am happy" and so on.

5.3.3. A Relaxing Tool for EFL Learners. Most of the time, EFL learners experience anxiety and peer pressure during the process of learning English, especially on the occasions when the new topics are introduced, the information load exceeds suddenly. Hence, when a teacher is planning a lesson for EFL students, it is vital to make sure that the lesson also offers a specific amount of time as a rest or relaxing period by incorporating a comparatively different activity with the same lesson objectives presented indirectly. For example, teaching the topic related to "Christmas" after introducing a handful of new vocabulary can overburden the student or tire them, so it is important to provide a relaxing yet relevant break between the two sessions by entertaining learners with Christmas-related songs. Hence, the songs used in EFL classrooms should not move away from the main topic or focus of teaching.

Moreover, the learner's tiredness or disinterest can be dealt with by playing a song with a video clip that can also display the meanings of lyrical words. Such kind of audio and visual content can be introduced in phases by starting with only displaying the video once or twice and if the song is not hard, you can encourage learners to sing along. If there is more time available, a small contest can be introduced and learners should be invited to give their best performances of the song they just heard. The winner can be treated with little prizes.

5.3.4. To Avoid the Affective Reasons. The affective factors are found more actively present during EFL learning when dealing with kindergarten students; given the age, many affective factors such as an uncomfortable crying learner who is new in the class or did not sleep well last night can 
interrupt the class and drive student's attention away from the teachers. In such cases, learners' attention is directed away from the teacher and is focused on the immediate situation.

In such a situation, to return the children's attention to the teacher, it is best to start a video with a song accompanied by great motor activity. Since children respond to music very quickly, they would get up immediately to perform and sing along with teacher. Children react very well and quickly to music, getting up from their seats, starting singing, and performing movements together with the teacher, as the teachers have successfully changed the immediate environment in the favour of learning.

5.3.5. Creative Solution for Difficult Tasks. In some EFL coursework activities, a teacher may encounter a task that learners find difficult. In such cases, the teacher needs to find a creative way to achieve the learning objectives by offering a less-pressure environment to students [7, 47], for example, teaching the alphabet to kindergarten learners with an age range of 2-3 years. Multiple popular alphabet songs can be used in this scenario such as ABC song in various variations and compositions available with both sounds and letters. However, considering the age factor, it is not possible to grab the attention of kindergartens with a song that has a lot of alphabets and sounds only that can create anxiety. In order to reduce the risk of psychological stress and anxiety, a phonic song with two words such as "a" for apple can be used along with letters and sounds. Such songs help the young learner to learn the sounds of letters along with memorizing two words for each letter. Since the kindergarten learners are too young, simple aids such as a flashcard corresponding to the words (ant, apple, ball, cat, cup, etc.) mentioned in the song can be helpful. During the lesson, children can play with these flashcards and identify the pictographic form of these alphabets in a fun way while singing simple songs. For young EFL learners, it is important that they are not overburdened with too many words. Hence, not more than four words a lesson is a decent limit for young EFL learners. It is important to make sure that learners pronounce each sound correctly and are able to distinguish it from other sounds. In order to make sure this happens, it is recommended to focus on involving each student individually before asking them to read along in a group as children can sing out and it can make it difficult for the teacher to spot errors in their pronunciations.

5.3.6. As a Time-Filling Activity. It is possible that sometimes a lesson runs smoothly enough to achieve all the learning objectives in time that can leave some free time at the end of the class. In such cases, it is important to use the extra time smartly as an opportunity for exposing EFL learners to an extra input relevant to the respective lesson through fun and pleasant activity that can offer both learning as well as motivation to the learners for further accomplishment. The one great idea to utilize this time is to conduct an activity that can help the learner to show their learning progress and at the same time offer an opportunity for the teacher to evaluate learners' progress so far. For example, a talent contest can be organized within the EFL classrooms, students can sing and perform the song they have learned so far, and teachers can notice the students who still need further revisions. This could enhance learners' love for the English language.

5.3.7. As an Aid of Learning New Linguistic Features. In some cases, the EFL learners have an aptitude for language that is below average, which can cause difficulty even in conveying simple concepts. For example, Vishnevskaia and Zhou [46] have found a similar problem while teaching the topic of likes and dislikes to Chinese EFL learners and realized that all the songs they had turned out to be more complicated for students. Hence, to counter this situation, they created a song by themselves. Therefore, whenever the EFL learners encounter lexical difficulty in the chosen songs, it is important for the teacher to come up with simplified versions of these songs to achieve the learning objectives. Vishnevskaia and Zhou [46] composed the following song and accompanied it with different movements to make it more interesting:

"I can fly and I can jump" (the children show how they fly, then they jump)

"I can walk and turn around" (the children show how they walk and turn around)

"I can sit and I can stand" (the children sit down and stand up)

"I can go and hug my friend" (the children go and hug each other)

\section{Conclusion}

The English songs represent the current picture of the world through the eye of native speakers. They can reflect the aspirations, motivations, cultural trends as well as the fears, anxieties, joys, and opinions through the lyrics that help EFL learners to comprehend the culture of the targeted language. Furthermore, many teachers, based on their experiences, evaluate songs as a helpful tool to solve many pedagogical problems in the EFL context. They also connect the foreign teacher with EFL learners and help them learn new linguistic patterns including multiple expressions quickly and smoothly. Songs also mitigate the stressful learning aspects by offering an easy, fun-filled environment for learning that can ease the cognitive burden of the EFL learners and can increase their motivation levels.

\section{Recommendations for Further Studies}

In view of the current findings, the researchers believe that a variety of empirical survey methods should be employed to conduct additional qualitative and quantitative study on this topic. Much more research is needed to determine the 
optimal way to incorporate music and songs into Englishlanguage learning contexts.

\section{The Limitation of the Study}

Researchers should proceed cautiously when interpreting current findings. The majority of the articles we looked at were comparative or correlational in nature, which was not surprising. As a result, drawing conclusions about causation is nonsensical. It is possible that musical intervention can improve foreign language ability by influencing a variety of external factors, some of which are described in this article.

\section{Data Availability}

The data are available from the corresponding author upon reasonable request.

\section{Conflicts of Interest}

The authors declare that they have no conflicts of interest.

\section{References}

[1] M. Ajmal and T. Kumar, "Using DIALANG in assessing foreign language proficiency: the interface between learning and assessment," Asian ESP Journal, vol. 16, no. 2.2, pp. 335-362, 2020.

[2] A. Gunasinghe, J. A. Hamid, A. Khatibi, and S. M. F. Azam, "The adequacy of UTAUT-3 in interpreting academician's adoption to e-learning in higher education environments," Interactive Technology and Smart Education, vol. 17, no. 1, pp. 86-106, 2019.

[3] K. S. Alemu and K. T. Ashagre, "Determinants of entrepreneurial intent among university students: a case of Ambo university," Journal of Asian and African Social Science and Humanities, vol. 1, no. 3, pp. 117-131, 2015.

[4] T. Kumar, V. Nukapangu, and A. Hassan, "Effectiveness of code-switching in language classroom in India at primary level: a case of L2 teachers' perspectives," Pegem Journal of Education and Instruction, vol. 11, no. 4, pp. 379-385, 2021.

[5] A. Benyo and T. Kumar, "An analysis of Indian EFL learners" listening comprehension errors," Asian ESP Journal, vol. 16, no. 5.2, pp. 69-85, 2020.

[6] K. Kumar, A. Prakash, and K. Singh, "How national education policy 2020 can be a lodestar to transform future generation in India," Journal of Public Affairs, vol. 21, no. 3, Article ID e2500, 2021.

[7] D. T. Kumar, "Social networking sites and grammar learning: the views of learners and practitioners," International Journal of Early Childhood Special Education, vol. 13, no. 2, pp. 215-223, 2021.

[8] M. G. M. Johar, M. S. Ab Yajid, and A. Khatibi, "Data mining technology and its applications for sales productivity analysis," Systematic Reviews in Pharmacy, vol. 11, no. 1, pp. 626-632, 2020.

[9] G. C. Magulod, L. B. Capulso, J. P. Dasig et al., "Attainment of the immediate program graduate attributes and learning outcomes of teacher candidates towards global competence initiatives," International Journal of Learning, Teaching and Educational Research, vol. 19, no. 12, 2021.

[10] C. Pantazidou, E. M. Vega-Gea, and B. E. S. Requena, "Relation between teachers' perception of language skills and social behaviors of students with dyslexia in central Macedonia (Greece)," Educational Sciences: Theory and Practice, vol. 21, no. 1, pp. 1-19, 2021.

[11] E. Yusuf and M. S. A. Yajid, "Halal pharmaceuticals and cosmeceuticals from the perspective of higher education," Asian Journal of Pharmaceutical Sciences, vol. 11, no. 1, pp. 18-19, 2016.

[12] R. Garner and P. A. Alexander, "Metacognition: answered and unanswered questions," Educational Psychologist, vol. 24, no. 2, pp. 143-158, 1989.

[13] T. Armstrong, Multiple Intelligences in the Classroom, ASCD, Alexandria, Virginia, USA, 2009.

[14] S. Ghory and H. Ghafory, "The impact of modern technology in the teaching and learning process," International Journal of Innovative Research and Scientific Studies, vol. 4, no. 3, pp. 168-173, 2021.

[15] D. I. E. P. Le Thi Ngoc and V. M. Hieu, "Examining quality of English language learning of university students in Vietnam: the moderating role of competition factor," Eurasian Journal of Educational Research, vol. 4, no. 95, pp. 55-79, 2021.

[16] M. A. Christison, "Teaching and learning languages through multiple intelligences," TESOL Journal, vol. 6, no. 1, pp. 10-14, 1996.

[17] D. G. Lazear, Teaching for Multiple Intelligences, Phi Delta Kappa Educational Foundation, Bloomington, Indiana, 1992.

[18] Y.-A. Hou, "Multiple intelligences and foreign language learning: a case study in Taiwan," The International Journal of the Humanities: Annual Review, vol. 8, no. 4, pp. 77-106, 2010.

[19] M. Ilyas and N. Afzal, "Teaching literary texts through cultural model to EFL students," Eurasian Journal of Applied Linguistics, vol. 7, no. 2, pp. 22-30, 2021.

[20] K. Hajhashemi, K. Akef, and N. Anderson, "The relationship between multiple intelligences and reading proficiency of Iranian EFL students," World Applied Sciences Journal, vol. 19, no. 10, pp. 1475-1483, 2012.

[21] G. Baş and Ö. Beyhab, "Effects of multiple intelligences supported project-based learning on students' achievement levels and attitudes towards English lesson," International Electronic Journal of Environmental Education, vol. 2, no. 3, pp. 365-386, 2010.

[22] M. S. Khaghaninejad and S. M. Hosseini, "The relationship between different types of multiple intelligence and lexical awareness: evidence from adult Iranian EFL learners," Modern Journal of Language Teaching Methods, vol. 4, no. 4, pp. 170-181, 2014.

[23] B. Laufer, "Vocabulary acquisition in a second language: do learners really acquire most vocabulary by reading? some empirical evidence," The Canadian Modern Language Review, vol. 59, no. 4, pp. 567-587, 2003.

[24] J. C. Richards and T. S. Rodgers, Approaches and Methods in Language Teaching, Cambridge University Press, Cambridge, UK, 2014.

[25] D. Beglar and A. Hunt, "Revising and validating the 2000word level and university word level vocabulary tests," Language Testing, vol. 16, no. 2, pp. 131-162, 2000.

[26] A. S. Abdelrady, S. F. Jahara, A. E. A. Elmadani, and T. Kumar, "The attitude of sudanese EFL students towards literature to enrich their vocabulary building," Educational Research International, vol. 2022, Article ID 7569371, 12 pages, 2022.

[27] F. Çakmak, E. Namaziandost, and T. Kumar, "CALL-enhanced 12 vocabulary learning: using spaced exposure through CALL to enhance 12 vocabulary retention," Educational Research International, vol. 2021, Article ID 5848525, 8 pages, 2021. 
[28] H. J. Weatherford, Techniques for Learning Vocabulary: Microfiche, ERIC Clearinghouse Microfiches, Washington, DC, USA, 1990.

[29] C. Reeve and J. Williamson, "Look what you're done to my song," Modern English Teacher, vol. 14, no. 4, pp. 33-36, 1987.

[30] C. D. Giudice, "How to exploit a song in class (we are the world)," Modern English Teacher, vol. 13, no. 2, pp. 7-8, 1986.

[31] P. Hubbard, H. Jones, B. Thornton, and R. Wheeler, A Training Course for TEFL, pp. 8-17, Oxford University Press, Oxford, UK, 1983.

[32] T. Murphey, Music and Song-Resource Books for Teachers, Oxford University Press, Oxford, UK, 2013.

[33] J. Piaget, "Part I: cognitive development in children: Piaget development and learning," Journal of Research in Science Teaching, vol. 2, no. 3, pp. 176-186, 1964.

[34] S. Krashen, Principles and Practice in Second Language Acquisition, Pergamon Press, Oxford, UK, 1983.

[35] A. Kuśnierek, "The role of music and songs in teaching English vocabulary to students," World Scientific News, vol. 1, no. 43 , pp. 1-55, 2016.

[36] A. Saricoban and E. Metin, "Songs, verse and games for teaching grammar," The Internet TESL Journal, vol. 6, no. 10, pp. $1-7,2000$.

[37] D. Griffee, "Songs and music techniques in foreign and second language classrooms," Cross Currents, vol. 15, no. 1, pp. 23-35, 1988.

[38] H. Gardner, Frames of Mind: The Theory of Multiple Intelligences, Basic Books, New York, NY, USA, 1983.

[39] L. Domoney and S. Harris, "Justified and ancient: pop music in EFL classrooms," ELT Journal, vol. 47, no. 3, pp. 234-241, 1993.

[40] A. J. Speh and S. D. Ahramjian, "Teaching without a common language: synchronicities between the pedagogies of music and second language acquisition," Bulletin of the Transilvania University of Braşov Series VIII, vol. 4, no. 53, pp. 77-82, 2011.

[41] D. K. Eken, "Ideas for using songs in the English language classroom," English Teaching Forum, vol. 34, no. 1, pp. 46-47, 1996.

[42] M. C. Fonseca-Mora, C. Toscano-Fuentes, and K. Wermke, "The relationship between language aptitude and musical intelligence," Anglistik International Journal of English Studies, vol. 22, no. 1, pp. 101-118, 2011.

[43] M. Z. Ocheretnyaya, "ШедаГоГическое сообщество УРОКРФ,” 2016.

[44] W. Baoan, "Application of popular English songs in EFL classroom teaching," Humanising Language Teaching, vol. 10, no. 3, 2008.

[45] I. P. Gubina, "Song as an effective means of teaching a foreign language (English) at the stage of secondary vocational education," Young Scientist, vol. 10, no. 4, pp. 11-15, 2017.

[46] M. Vishnevskaia and Z. Zhou, "The impact of using music and songs on teaching EFL in China by non-native English teachers," Universal Journal of Educational Research, vol. 7, no. 8, pp. 1808-1813, 2019.

[47] T. Kumar, "Approaches in teaching writing skills with creative writing: a TESOL study for Indian learners," TESOL International Journal, vol. 15, no. 5, pp. 78-98, 2020. 